\title{
Management of advanced breast cancer with the epothilone $B$ analog, ixabepilone
}

This article was published in the following Dove Press journal:

Drug Design, Development and Therapy

26 May 2009

Number of times this article has been viewed

\section{William Gradishar \\ Robert H Lurie Comprehensive Cancer Center, Northwestern University Feinberg School of Medicine, Chicago, IL, USA}

Correspondence: William J Gradishar Robert H Lurie Comprehensive Cancer Center, Northwestern University Feinberg School of Medicine, 676 North St. Clair, Suite 850, Chicago, IL, 606II, USA

Tel + | 3|2-695-454|

$\mathrm{Fax}+1$ 312-695-6189

Email w-gradishar@northwestern.edu

\begin{abstract}
Despite the activity of standard chemotherapies in advanced breast cancer, disease progression remains inevitable. Most patients exposed to anthracyclines and taxanes develop resistance and a significant subset shows primary resistance. The increasing use of these agents as adjuvant therapy may result in more anthracycline- and taxane-resistant patients in the metastatic setting; few treatment options are available for patients with metastatic breast cancer (MBC) resistant to multiple chemotherapies. The heterogeneity of breast cancer represents another therapeutic challenge. Breast cancers may be classified as luminal, human epidermal growth factor 2 (HER2)-positive, or estrogen receptor-, progesterone receptor-, and human epidermal growth factor 2-negative (ER/PR/HER2-negative, triple negative). HER2-positive and ER/PR/HER2-negative tumors are associated with poor prognosis owing to aggressive disease and poor long-term response to therapy. The epothilone B analog ixabepilone has low susceptibility to multiple mechanisms of resistance and has demonstrated activity in patients with $\mathrm{MBC}$ resistant to anthracyclines, taxanes, and/or capecitabine. Ixabepilone is the first epothilone to be approved, as monotherapy or in combination with capecitabine, for treatment of resistant/refractory MBC or locally advanced breast cancer. Treatment with ixabepilone is an option for patients with ER/PR/HER2-negative or HER2-positive disease and/or primary resistance to taxanes.
\end{abstract}

Keywords: breast cancer, drug resistance, epothilone, HER2-positive, ixabepilone, ER/PR/ HER2-negative (triple negative)

\section{Introduction}

In the United States, an estimated 184,450 new cases of breast cancer will be diagnosed in 2008. Of these, almost 41,000 patients are expected to die from the disease. ${ }^{1}$ Approximately $10 \%$ of patients have metastatic disease at the time of diagnosis, and $20 \%$ to $85 \%$ of patients with early-stage breast cancer will eventually develop metastatic disease. ${ }^{2,3}$ Patients with metastatic breast cancer (MBC) treated with anthracyclineand/or taxane-based chemotherapy, ${ }^{3}$ have overall response rates (ORR) of $32 \%$ to $68 \% .{ }^{4,5}$ However, the benefits are relatively short-lived; median duration of response (DOR) ranges from 8 to 14 months, ${ }^{2}$ median survival is 2 to 3.5 years, ${ }^{2,3}$ and the 5 -year survival rate is approximately $27 \%{ }^{6}$ Progression of MBC remains inevitable, and the majority of patients will eventually die of the disease. ${ }^{7}$

One significant factor that limits the efficacy of standard therapies for MBC is multidrug resistance (MDR), which can be either primary (preceding drug exposure) or acquired resistance (induced by treatment). ${ }^{4}$ Drug resistance is considered the cause of treatment failure in more than $90 \%$ of all patients with metastatic cancer. ${ }^{8}$ Mechanisms

submit your manuscript | www.dovepress.con 
of MDR include overexpression of $\beta$ III-tubulin isotypes, and drug efflux transporters such as P-glycoprotein (P-gp) and multidrug resistance protein 1 (MRP1). ${ }^{9}$

Altered expression of $\beta$ III-tubulin in cancer cells is associated with increased resistance to microtubule inhibitors such as the taxanes. ${ }^{10}$ Overexpression of $\beta$ III-tubulin alters microtubule assembly properties in vitro, resulting in a slower rate of polymerization and decreasing sensitivity to the microtubule-stabilizing taxanes. ${ }^{11}$ The decrease in sensitivity to paclitaxel in $\beta$ III-tubulin overexpressing cells appears associated with reduced binding to $\beta I I I-t u b u l i n$ and/or the inability to induce conformational changes that suppress microtubule dynamics. ${ }^{12}$ Molecular modeling studies predict that paclitaxel binds to $\beta$ III-tubulin with reduced affinity versus $\beta$ I-tubulin. ${ }^{13}$

Increased levels of $\beta$ III-tubulin have been observed in many tumor types, including breast, lung, ovarian, pancreatic, and prostate cancer cell lines. ${ }^{10} \mathrm{~A}$ univariate analysis in $\mathrm{MBC}$ showed a predictive correlation between $\beta$ III-tubulin expression and clinical response to paclitaxel-based chemotherapy. ${ }^{14}$ Patients with lower levels of $\beta$ III-tubulin had improved tumor control following treatment with paclitaxel than those with high expression of $\beta$ III-tubulin. Increased $\beta$ III-tubulin expression has also been associated with poor prognosis as well as shorter progression-free and overall survival in patients with breast, lung, and ovarian cancers. ${ }^{10,14,15}$

Drug efflux transporters reduce intracellular concentrations of hydrophobic drugs such as anthracyclines and taxanes by pumping them out of cells. ${ }^{9}$ Strong evidence of the role of these proteins in drug resistance has been obtained using tumor cell lines and animal models. ${ }^{9}$ However, evaluation of their role in development of clinical drug resistance has been hampered by differences in methods used to assess their expression and by the heterogeneity of tumor specimens used for analysis. ${ }^{16}$ It is important to stress that analysis of a single mechanism does not fully capture the complex interactions between multiple cellular pathways that are necessary to produce the MDR phenotype. Additionally, it is likely that a number of mechanisms with important roles in development of drug resistance remain to be elucidated. Nonetheless, several lines of evidence strongly support an important role for drug efflux transporters in the development of clinical drug resistance. The proteins have been shown to be overexpressed in many human tumor types and their expression is associated with acquisition of drug resistance and with poor response to chemotherapy. Additionally, increased expression levels of P-gp and MRP-1 occur following exposure to chemotherapy in both normal and tumor cells. ${ }^{17,18}$
A meta-analysis of trials in breast cancer demonstrated that over $40 \%$ of untreated breast tumors express P-gp (41.2\%) and MRP-1 (49\%) as assessed by immunohistochemistry (IHC). ${ }^{19}$ When assessed using polymerase chain reaction (PCR), expression of P-gp and MRP-1 was detected in $61 \%$ and $98 \%$ of untreated breast tumors, respectively. ${ }^{19}$ Importantly, exposure to chemotherapy increased the expression of both proteins and P-gp expression was linked to a 3 -fold increase in the risk of treatment failure. ${ }^{20,21}$ The data also indicate a trend toward worse prognosis in breast cancer patients with early expression of MRP1. ${ }^{19}$

Most patients exposed to anthracyclines and taxanes develop resistance ${ }^{4}$ precluding long-term use of these agents and further limiting treatment options for this poor prognosis group. Furthermore, up to $55 \%$ of patients with MBC have primary taxane-resistance, defined as progressive disease as best response to taxane therapy. ${ }^{22,23}$ Treatment options for MBC patients following failure of anthracycline- and taxanebased therapy include agents such as capecitabine, gemcitabine, and vinorelbine. Response rates with gemcitabine and vinorelbine are $16 \%$ to $30 \%$, and duration of response ranges from 4 to 7 months. ${ }^{24}$ Single-agent capecitabine, which is approved for use in $\mathrm{MBC}$ after prior anthracyclines and taxanes, demonstrated ORRs ranging from $9 \%$ to $28 \%$, with median duration of response of 5.9 to 7.6 months. ${ }^{25-27}$ Efforts have focused on identifying new effective agents or combination regimens that provide benefit to patients with $\mathrm{MBC}$ resistant to multiple chemotherapies in terms of improved tumor control and survival.

\section{Epothilones}

Isolated from the myxobacterium Sorangium cellulosum, epothilones are a novel class of antineoplastic agents that promote polymerization of microtubules. ${ }^{28}$ Epothilones and taxanes occupy overlapping areas in the taxane-binding site on microtubules. ${ }^{29}$ However, the unique way in which the epothilones bind leads to differences in their mechanism of action compared with taxanes. Epothilones maintain activity against taxane-sensitive and -resistant cell lines, including those overexpressing $\beta$ III-tubulin and P-gp. Molecular modeling studies predict distinct $\beta$-tubulin binding properties for epothilone A and paclitaxel. A similar binding affinity to $\beta \mathrm{I}$ and $\beta$ III-tubulin is predicted for epothilone $\mathrm{A}$ while paclitaxel is predicted to have higher binding affinity to $\beta \mathrm{I}-$ tubulin. ${ }^{13}$ As poor substrates for drug efflux pumps, epothilones are highly active against MDR cell lines, in vitro and in vivo. ${ }^{28,30}$ The naturally occurring epothilones patupilone (epothilone B, EPO906), and KOS862 (epothilone D), as well 
as the semisynthetic derivatives ixabepilone (BMS-247550, aza-epothilone), KOS-1584 (9,10,-didehydroepothilone), and ZK-epothilone (ZK-EPO, ZK-219477, sagopilone) have shown activity and distinct safety profiles in patients with advanced solid malignancies. ${ }^{31}$ Ixabepilone, the first approved drug in this class, is indicated as monotherapy or in combination with capecitabine for the treatment of patients with MBC resistant to anthracyclines, taxanes, and/or capecitabine. The other epothilones mentioned above are in various stages of clinical development, with the exception of KOS862, which has been discontinued in prostate and non-small-cell lung cancer.

\section{Ixabepilone}

Ixabepilone has low susceptibility to common mechanisms of resistance. For example, ixabepilone is active against Pat-21 tumor xenografts. ${ }^{32}$ Pat-21 is a tumor model developed from a patient with MBC after failure of paclitaxel plus the MDR reversal drug dexverapamil. The patient had also received doxorubicin, cyclophosphamide, methotrexate, and 5-fluorouracil. Pat-21 cells have high levels of $\beta$ III-tubulin but do not overexpress P-gp. The overexpression of $\beta$ III-tubulin in the Pat-21 breast cancer model did not affect sensitivity to ixabepilone, whereas Pat-21 tumor xenografts were resistant to paclitaxel and docetaxel. ${ }^{32}$ In addition, ixabepilone is active in taxaneresistant cell lines including the P-gp overexpressing HCT116/ VM46 (human colon carcinoma) and A2780Tax (human ovarian carcinoma) with mutated $\beta$-tubulin, and maintains activity in taxane-sensitive and -resistant tumor xenografts. ${ }^{30} \mathrm{In}$ preclinical models, ixabepilone demonstrated synergistic activity when used in combination with capecitabine, cetuximab, trastuzumab, bevacizumab, or ipilimumab. ${ }^{33-36}$

\section{Efficacy of ixabepilone in metastatic breast cancer}

As a single agent or in combination with capecitabine, ixabepilone is efficacious across a range of patients with MBC including taxane-naïve, anthracycline-, taxane-, and/or capecitabine-resistant patients, as well as those with primary resistance to taxanes. Ixabepilone has proven efficacy in different breast cancer subtypes; patients with estrogen receptor, progesterone receptor, and human epidermal growth factor receptor 2-negative (ER/PR/HER2-negative, triple negative) or HER2-positive disease have derived clinical benefit from ixabepilone treatment. Ixabepilone has been administered as first-, second or, third line in MBC as well as in the neoadjuvant setting, and has demonstrated efficacy across all lines of therapy evaluated.

\section{Monotherapy}

In a phase II study, Roché and colleagues administered ixabepilone at the recommended dose of $40 \mathrm{mg} / \mathrm{m}^{2}$ as an intravenous (iv) infusion over 3 hours every 3 weeks as first-line metastatic therapy to $65 \mathrm{MBC}$ patients who had received anthracyclines in the adjuvant setting. Twenty-seven patients had a partial response (ORR 41.5\%), median time to progression (TTP) was 4.8 months, and median overall survival (OS) was 22.0 months. ${ }^{37}$ The phase II study conducted by Thomas and colleagues reported an ORR of $12 \%$ (6 partial responses) in 49 patients with taxane-resistant $\mathrm{MBC}$ who received ixabepilone. Median TTP was 2.2 months, with a median OS of 7.9 months. ${ }^{38}$ Perez and colleagues conducted a phase II study of ixabepilone in MBC patients with anthracycline-, taxane-, and capecitabine resistance. Of 126 patients treated with ixabepilone, 113 were evaluable for response. The ORR was $11.5 \%$, with 13 partial responses (Table 1). Median progression-free survival (PFS) was 3.1 months, and median OS was 8.6 months. ${ }^{39}$

An alternative dose and schedule of ixabepilone has been evaluated in MBC. Denduluri and colleagues evaluated the activity of ixabepilone $6 \mathrm{mg} / \mathrm{m}^{2} / \mathrm{d}$ iv over 1 hour on days 1 to 5 every 3 weeks in 23 taxane-naïve patients with $\mathrm{MBC}$, 12 of whom $(52 \%)$ had received prior anthracyclines. The ORR was 57\% (13 partial responses), and median TTP was 5.5 months. Seven of 12 (58\%) patients who had prior anthracyclines had partial responses. ${ }^{40}$ In another phase II study, 37 taxane-refractory $\mathrm{MBC}$ patients received ixabepilone $6 \mathrm{mg} / \mathrm{m}^{2} / \mathrm{d}$ iv over 1 hour on days 1 to 5 every 3 weeks. Ixabepilone treatment resulted in an ORR of $22 \%$, with 1 complete response and 7 partial responses (Table 1), and a median TTP of 2.6 months. $^{41}$

\section{Combination therapy}

Based on the single-agent activity and demonstrated synergy in preclinical models ${ }^{35}$ an ixabepilone plus capecitabine regimen was evaluated in a phase I/II study with anthracycline- and taxane-resistant MBC patients. The recommended dose for the combination regimen was ixabepilone $40 \mathrm{mg} / \mathrm{m}^{2}$ iv over $3 \mathrm{~h}$ every 3 weeks and oral capecitabine $2000 \mathrm{mg} / \mathrm{m}^{2}$ administered in 2 divided doses daily on days 1 to 14 every 3 weeks. Of 50 evaluable patients, 1 complete response and 14 partial responses were observed (ORR 30\%) and median PFS was 3.8 months. $^{42}$ A large randomized phase III study compared the ixabepilone plus capecitabine combination with capecitabine monotherapy in 752 patients with anthracyclineand taxane-resistant $\mathrm{MBC} .{ }^{43}$ Patients were randomly assigned to receive ixabepilone plus capecitabine $(\mathrm{N}=375)$ 
Table I Efficacy of ixabepilone monotherapy in metastatic breast cancer

\begin{tabular}{|c|c|c|c|c|c|}
\hline Investigator & Roché et $\mathrm{al}^{37}$ & Thomas et al ${ }^{38}$ & Perez et $\mathrm{al}^{39}$ & Low et $\mathrm{al}^{41}$ & Denduluri et $\mathrm{al}^{40}$ \\
\hline Patient population & A-resistant & T-resistant & A-,T-, C-resistant & T-resistant & T-naïve \\
\hline Patient number & $N=65$ & $N=49$ & $N=113$ & $N=37$ & $N=23$ \\
\hline Dosing schedule & \multicolumn{3}{|c|}{40 mg/m²; 3-hour iv infusion; day I; Q3W } & \multicolumn{2}{|c|}{$6 \mathrm{mg} / \mathrm{m}^{2}$; I-h iv infusion; days I to $5 \mathrm{Q} 3 \mathrm{~W}$} \\
\hline $\begin{array}{l}\text { Median ORR (\%) } \\
{[95 \% \mathrm{Cl}]}\end{array}$ & $\begin{array}{l}41.5 \\
{[29.4 \text { to } 54.4]}\end{array}$ & $\begin{array}{l}\text { I2.2 } \\
\text { [4.7 to } 26.5 \text { ] }\end{array}$ & $\begin{array}{l}\text { II.5 } \\
\text { [6.3 to 18.9] }\end{array}$ & $22[9.8$ to 38.2$]$ & $57[34.5$ to 76.8$]$ \\
\hline $\begin{array}{l}\text { Median PFS (mo) } \\
{[95 \% \mathrm{Cl}]}\end{array}$ & $\begin{array}{l}\text { (TTP) } 4.8 \\
{[4.2 \text { to } 7.6]}\end{array}$ & $\begin{array}{l}\text { (TTP) } 2.2 \\
{\left[\begin{array}{l}1.4 \text { to } 3.2]\end{array}\right.}\end{array}$ & $\begin{array}{l}3.1 \\
{[2.7 \text { to } 4.2]}\end{array}$ & $\begin{array}{l}2.6 \\
{[N R]}\end{array}$ & $\begin{array}{l}\text { (TTP) } 5.5 \\
{[\mathrm{NR}]}\end{array}$ \\
\hline $\begin{array}{l}\text { Median OS (mo) } \\
{[95 \% \mathrm{Cl}]}\end{array}$ & $\begin{array}{l}22.0 \\
{[15.6 \text { to } 27.0]}\end{array}$ & $\begin{array}{l}7.9 \\
{[6.1 \text { to } 14.5]}\end{array}$ & $\begin{array}{l}8.6 \\
{[6.9 \text { to } 11.1]}\end{array}$ & {$[N R]$} & {$[N R]$} \\
\hline
\end{tabular}

Abbreviations: A, anthracycline; C, capecitabine; iv, intravenous; NR, not reported; ORR, overall response rate; OS, overall survival; PFS, progression-free survival; T, taxane; TTP, time to progression.

or capecitabine alone $(\mathrm{N}=377)$ (Table 2). Ixabepilone plus capecitabine treatment led to a $31 \%$ decrease in the risk of disease progression (hazard ratio [HR] $0.69 ; 95 \%$ confidence interval [CI], 0.58-0.83; $\mathrm{p}<0.0001$ ), and a $39 \%$ increase in median PFS (5.7 months compared with 4.1 months in the capecitabine monotherapy arm) ${ }^{44}$ The combination regimen was superior to capecitabine, with ORRs of $35 \%$ vs $14 \%$ in the respective treatment arms. ${ }^{43}$ The overall survival data are expected in 2009.

\section{Safety and tolerability of ixabepilone \\ Monotherapy}

Ixabepilone has demonstrated a manageable safety profile in chemonaïve, and in mildly or heavily pretreated patients as a single agent. Neutropenia and peripheral sensory neuropathy were the most frequently noted grade $3 / 4$ adverse events with the administration of ixabepilone $40 \mathrm{mg} / \mathrm{m}^{2}$ every 3 weeks; febrile neutropenia was uncommon (Table 3). Grade 3/4 neutropenia reported with ixabepilone $40 \mathrm{mg} / \mathrm{m}^{2} \mathrm{Q} 3 \mathrm{~W}$ monotherapy ranged from $53 \%$ to $58 \%$, and was generally manageable. ${ }^{37-39}$ Febrile neutropenia occurred in $\leq 6 \%$ of patients in these trials (Table 1). At the alternate dosage $\left(6 \mathrm{mg} / \mathrm{m}^{2} / \mathrm{d}\right.$ iv over 1 hour on days 1 to 5 every 3 weeks), grade $3 / 4$ neutropenia occurred in $22 \%$ and $35 \%$ of patients. ${ }^{40,41}$ The incidence of grade $3 / 4$ febrile neutropenia ranged from $0 \%$ and $14 \%{ }^{40,41}$ Peripheral sensory neuropathy was primarily grade $1 / 2$, even in heavily pretreated patients. Grade $3 / 4$ sensory neuropathy occurring in $12 \%$ to $20 \%$ of patients was cumulative and mostly reversible, resolving to baseline or grade 1 within a median of 5.4 weeks following dose adjustments or treatment delay. ${ }^{45}$ Discontinuation of ixabepilone is

Table 2 Efficacy of ixabepilone plus capecitabine in metastatic breast cancer

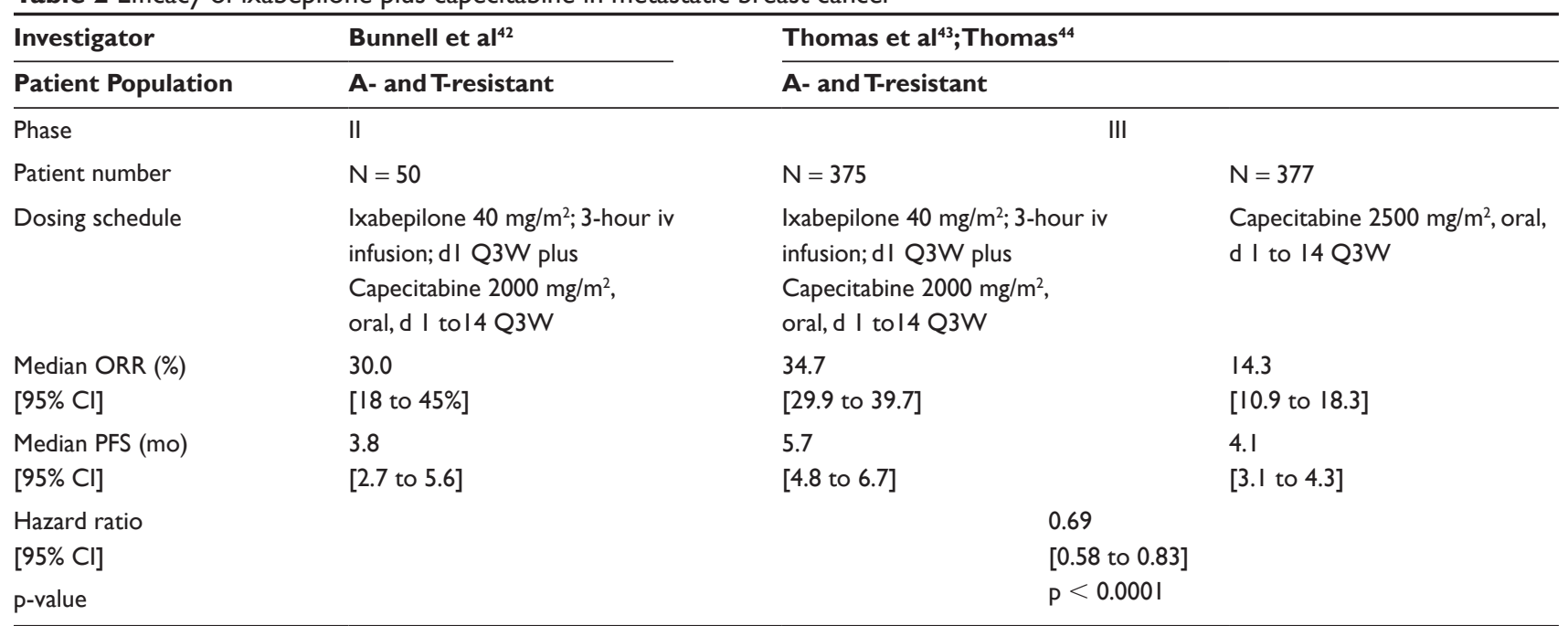

Abbreviations: A, anthracycline; iv, intravenous; NR, not reported; ORR, overall response rate; OS, overall survival; PFS, progression-free survival; T, taxane. 


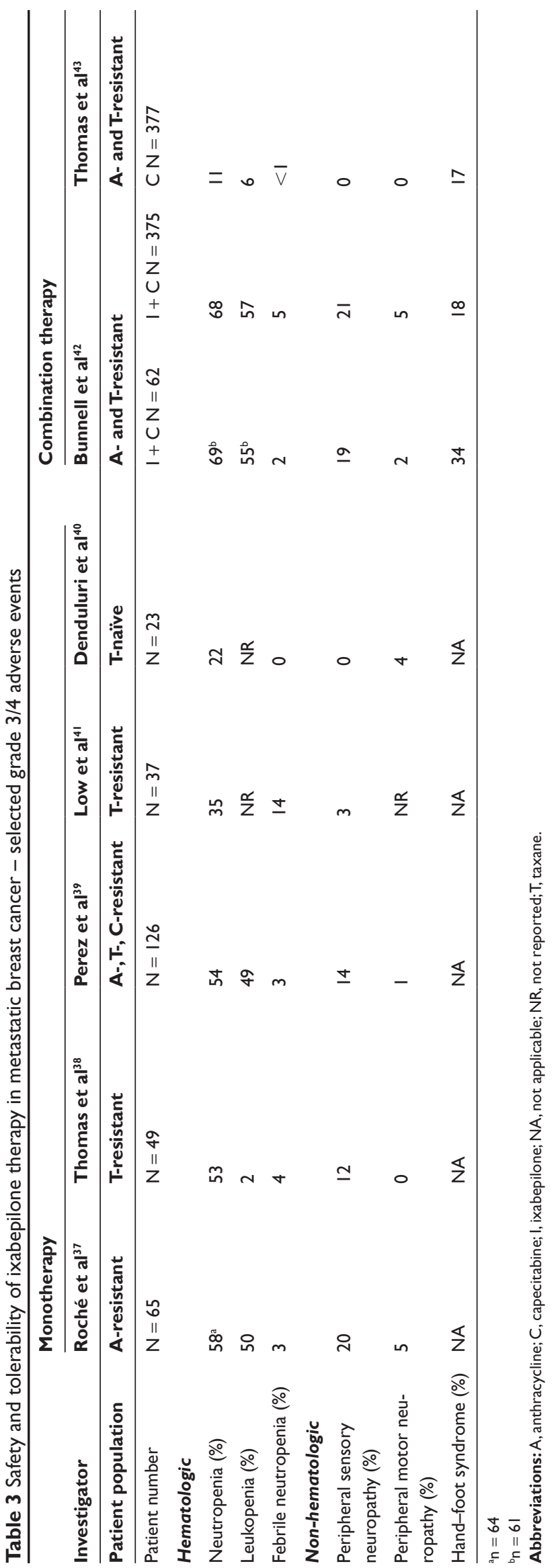

recommended in patients with grade 3 neuropathy $\geq 7$ days or any grade 4 neuropathy. ${ }^{46}$ A $20 \%$ dose reduction is recommended in patients with grade 2 neuropathy $\geq 7$ days or grade 3 neuropathy $<7$ days. ${ }^{46}$ The trials of the lower ixabepilone dose $\left(6 \mathrm{mg} / \mathrm{m}^{2} /\right.$ day iv over 1 hour on days 1 to 5 every 3 weeks) reported fewer incidences of grade 3/4 peripheral sensory neuropathy ( $\leq 3 \%$ ) (Table 3 ). ${ }^{40,41}$ Grade $3 / 4$ peripheral motor neuropathy was noted in $\leq 5 \%$ of patients at standard ixabepilone dosing. ${ }^{37-39}$ Other grade $3 / 4$ adverse events noted with ixabepilone treatment include fatigue ( $6 \%$ to $27 \%$ ), myalgia/arthralgia ( $3 \%$ to $13 \%$ ), and diarrhea $(1 \%$ to $11 \%) .37-41$

\section{Combination therapy}

Adverse events associated with the ixabepilone plus capecitabine combination were consistent with the safety profile of the individual agents (Table 3). Grade 3/4 adverse events reported in patients receiving ixabepilone plus capecitabine included neutropenia (68\%), leukopenia (57\%), and peripheral sensory neuropathy $(21 \%) .{ }^{43}$ There was an increased risk of severe neutropenia, febrile neutropenia, and neutropenia-related toxic death in the ixabepilone plus capecitabine treatment arm versus capecitabine monotherapy. Grade $3 / 4$ febrile neutropenia was $4.8 \%$ and $0.5 \%$ in the combination and capecitabine monotherapy arms, respectively. ${ }^{43}$ Owing to the hepatic metabolism of ixabepilone, investigators noted a higher risk of toxicity in patients receiving Ixabepilone and capecitabine with moderate or severe hepatic impairment at baseline. Neutropenia-related deaths occurred in 7 of 353 patients (1.9\%) with moderate (grade $0 / 1$ ) baseline liver impairment, and in 5 of 16 patients $(31 \%)$ with severe (grade $\geq 2$ ) baseline hepatic dysfunction. ${ }^{43}$ Dose adjustments have been recommended for patients with moderate or severe liver dysfunction receiving ixabepilone monotherapy. ${ }^{47}$ The ixabepilone plus capecitabine combination is contraindicated in patients with AST or ALT $>2.5 \times$ upper limit of normal (ULN) or bilirubin $>1 \times \mathrm{ULN}^{.46}$ Conversely, patients with normal or mild hepatic impairment had prolongation of PFS by 2.0 months compared to capecitabine alone (6.2 vs 4.2 months; HR, 0.73). ${ }^{43}$ Peripheral sensory neuropathy occurred in $65 \%$ of patients in the ixabepilone plus capecitabine arm, and was generally mild to moderate (grade $1 / 2,44 \%$; grade $3 / 4,21 \%){ }^{43}$ Grade $3 / 4$ peripheral sensory neuropathy was manageable with dose adjustments and reversible; $89 \%$ of patients had resolution to baseline or grade 1 within a median of 6.0 weeks. ${ }^{48}$ Rates of grade 3/4 hand-foot syndrome were nearly equivalent, $18 \%$ with ixabepilone plus 
capecitabine and $17 \%$ with capecitabine monotherapy. ${ }^{43}$ In the phase III trial, $11 \%$ of patients in the ixabepilone plus capecitabine arm had grade 3/4 myalgia/arthralgia versus $0.3 \%$ in the capecitabine monotherapy arm. ${ }^{43}$ Grade $3 / 4$ fatigue was experienced by $9 \%$ versus $3.3 \%$ of patients receiving ixabepilone plus capecitabine and capecitabine monotherapy, respectively. Grade 3/4 diarrhea was reported in $6 \%$ and $8.5 \%$ of patients in the respective arms. ${ }^{43}$

\section{Efficacy of ixabepilone in specific MBC patient subpopulations}

Approximately $10 \%$ to $25 \%$ of all breast cancer cases are ER/PR/HER2-negative ${ }^{49-52}$ and primary taxane resistance has been observed in up to $55 \%$ of breast cancer patients. ${ }^{22,23}$ Patients who fall into these categories generally have a poorer prognosis and shorter survival compared with their counterparts. ${ }^{49,51}$ Effective treatment options are limited for the sizeable portion of breast cancer patients in these subpopulations largely affected by aggressive disease. Ixabepilone has demonstrated efficacy in patients with ER/ PR/HER2-negative or HER2-positive disease, as well as those with primary taxane resistance, and represents a novel therapeutic option for these populations (Tables 4 and 5).

Subgroup analyses of ER/PR/HER2-negative patients in 3 phase II trials evaluated the activity of ixabepilone in this poor prognosis population. Eleven of 65 patients in the trial conducted by Roché and colleagues had ER/PR/ HER2-negative disease. The response to ixabepilone monotherapy in this subpopulation was 55\% with median PFS of 4.6 months. ${ }^{53}$ Eighteen of 49 patients in the phase II trial by Thomas and colleagues were ER/PR/HER2-negative; following ixabepilone treatment, the ORR in these patients was $6 \%$ and median PFS was 1.6 months. ${ }^{53}$ The trial conducted by Perez et al included 42 ER/PR/HER2-negative patients of the 126 enrolled. The ORR was $12 \%$, and median PFS was 2.7 months. In the neoadjuvant setting, the ORR was $64 \%$ and the pathologic complete response in breast $\left(\mathrm{pCR}_{\mathrm{B}}\right)$ was $26 \%$ in patients with ER/PR/HER2-negative disease receiving up to 4 cycles of ixabepilone $40 \mathrm{mg} / \mathrm{m}^{2}$ every 3 weeks versus $18 \%$ in the overall patient population..$^{53,54}$

Prospective analyses of specific patient subpopulations in the phase III trial of ixabepilone plus capecitabine versus capecitabine alone showed superiority of the combination regimen. In the ixabepilone plus capecitabine arm, 91 patients (24\%) were ER/PR/HER2-negative, 164 (44\%) were ER-negative, 59 (16\%) were HER2-positive, and $150(40 \%)$ had primary taxane resistance. Patients with ER/PR/HER2-negative disease had an ORR of $27 \%$ following treatment with the combination versus $9 \%$ with the capecitabine monotherapy. ${ }^{48}$ The ixabepilone plus capecitabine combination improved median PFS compared with capecitabine alone; 4.1 versus 2.1 months $(\mathrm{HR}=0.68) .{ }^{48}$ The ER-negative population also had improved median PFS; 4.4 versus 2.8 months $(\mathrm{HR}=0.65, \mathrm{p}<0.0001)$. The ORRs were $30 \%$ and $10 \%$ for ER-negative patients in the combination and capecitabine monotherapy arms, respectively (Table 5) ${ }^{55}$ Ixabepilone plus capecitabine improved median PFS in HER2-positive patients; 5.3 versus 4.1 months with capecitabine alone $(\mathrm{HR}=0.69, \mathrm{p}=0.06)$. The ORRs were $31 \%$ and $8 \%$ in the respective arms. ${ }^{56}$ Safety and tolerability of ixabepilone in the patient subpopulations were similar to the overall population. ${ }^{48,53,57}$

Subset analyses demonstrated efficacy of ixabepilone mono- or combination therapy in MBC patients with primary taxane resistance, defined as progressive disease as best response to prior taxanes. In the phase III study, patients in the ixabepilone plus capecitabine arm had a median PFS of 5.6 months versus 4.9 months in the capecitabine arm; ORRs were $33 \%$ vs $13 \%$, respectively. ${ }^{57}$ Similarly, in a phase II trial, ixabepilone was active as monotherapy in MBC patients with primary taxane resistance..$^{39,57}$

\section{Conclusions}

Disease progression in $\mathrm{MBC}$ is common. The increasing use of anthracycline- and taxane-based regimens in the adjuvant setting and the development of resistance to these agents

Table 4 ER/PR/HER2-negative metastatic breast cancer - efficacy of ixabepilone monotherapy

\begin{tabular}{|c|c|c|c|}
\hline Investigator & Roché et al $^{37}$ & Thomas et $a^{38}$ & Perez et $\mathbf{a l}^{39}$ \\
\hline Patient population & A-resistant & T-resistant & A-,T-, C-resistant \\
\hline Number of ER/PR/HER2-negative patients & $N=11$ & $N=18$ & $N=42$ \\
\hline Median ORR (\%) & $55 \%$ & $6 \%$ & $12 \%$ \\
\hline Median PFS (months) $[95 \% \mathrm{Cl}]$ & $4.6[2.8$ to 9.3$]$ & $1.6[1.3$ to 2.3$]$ & $2.7[1.5$ to 5.9$]$ \\
\hline
\end{tabular}

Notes: Ixabepilone $40 \mathrm{mg} / \mathrm{m}^{2}$ administered once every 3 weeks.

Abbreviations: A, anthracycline; C, capecitabine; ER, estrogen receptor; HER2, human epidermal growth factor 2; NR, not reported; ORR, overall response rate; $\mathrm{PR}$, progesterone receptor; $\mathrm{PFS}$, progression-free survival; $\mathrm{T}$, taxane. 


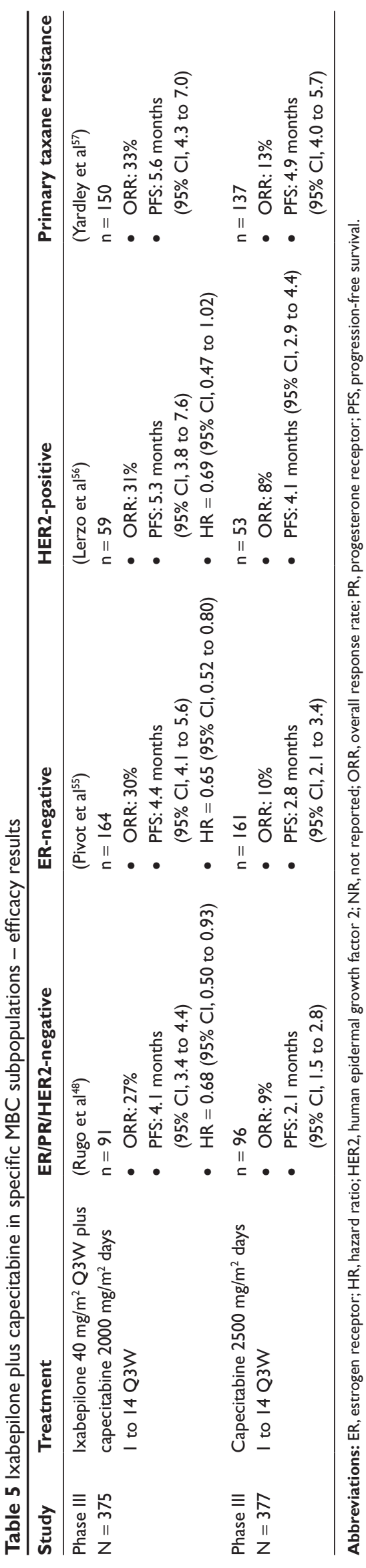

limit their efficacy against metastatic disease. Few agents have demonstrated activity after failure of anthracyclines and taxanes and in most cases, with little effect on disease progression.

Higher response rates were observed in taxane naïve and/ or anthracycline pretreated patients receiving ixabepilone. Reduced response rates were observed in patients resistant to taxanes or anthracyclines, taxanes and capecitabine (Table 1). These data are consistent with previously observed reduction in therapeutic efficacy in patients who have developed resistance to one or more chemotherapeutic agents and/or with increasing lines of therapy. ${ }^{58}$ Nonetheless, consistent with the preclinical data, the results suggest that ixabepilone may overcome and/or circumvent at least some of the cellular mechanisms that block taxane-, anthracycline- and/or capecitabine-induced cytotoxicity.

Overall, the clinical studies have demonstrated that ixabepilone:

- Has low susceptibility to common mechanisms of drug resistance, such as $\beta$ III tubulin overexpression.

- Is efficacious against anthracycline- and taxane-pretreated MBC.

- Has a manageable safety profile.

- Provides significant clinical benefit to patients with ER/ PR/HER2-negative and HER2-positive disease, and/or patients with primary resistance to taxanes.

Based on the data from the phase II and III trials in MBC, ixabepilone received approval from the United States Food and Drug Administration (FDA) for use in combination with capecitabine for the treatment of patients with MBC resistant to anthracyclines and taxanes, and as monotherapy for MBC patients resistant or refractory to anthracyclines, taxanes, and capecitabine. However, the European Medicines Agency (EMEA) Committee for Medicinal Products for Human Use (CHMP) did not approve marketing authorization for ixabepilone citing concerns over treatment-related neuropathy.

A recently completed analysis of survival data from the 2 large phase III ixabepilone trials in MBC demonstrated a trend towards increased OS that did not reach statistical significance. ${ }^{59}$ However, an OS benefit was reported in patients treated with ixabepilone following a pre-defined Cox Regression analysis with data adjusted according to prognostic factors. ${ }^{60}$

A number of ongoing trials are evaluating ixabepilone in combination with other chemotherapeutic and biologic agents for treatment of a variety of tumor types. A preliminary report indicates that ixabepilone in combination with epirubicin is active in patients with MBC. ${ }^{61}$ Additionally, an overall 
response rate of $53.8 \%$ was reported for ixabepilone in combination with trastuzumab in patients with HER2-positive metastatic breast cancer. ${ }^{62}$ The results of additional trials examining ixabepilone combination therapy in patients with MBC are anticipated in 2009.

\section{Disclosures}

The author has no conflicts of interest to disclose.

\section{References}

1. Jemal A, Siegel R, Ward E, et al. Cancer statistics. CA Cancer J Clin. 2008;58:71-96.

2. Greenberg PA, Hortobagyi GN, Smith TL, et al. Long-term follow-up of patients with complete remission following combination chemotherapy for metastatic breast cancer. J Clin Oncol. 1996;14: 2197-2205.

3. Bernard-Marty C, Cardoso F, Piccart MJ. Facts and controversies in systemic treatment of metastatic breast cancer. Oncologist. 2004;9: 617-632.

4. O'Driscoll L, Clynes M. Biomarkers and multiple drug resistance in breast cancer. Curr Cancer Drug Targets. 2006;6:365-84.

5. Cortes J, Baselga J. Targeting the microtubules in breast cancer beyond taxanes: the epothilones. Oncologist. 2007;12:271-280.

6. Ries LA, Melbert DKM, Mariotto A, et al. SEER Cancer Statistics Review. 2007;1975-2004.

7. Hortobagyi GN. Treatment of breast cancer. N Engl J Med.1998;339: 974-984.

8. Longley DB, Johnston PG. Molecular mechanisms of drug resistance. J Pathol. 2005;205:275-292.

9. Gottesman MM. Mechanisms of cancer drug resistance. Annu Rev Med. 2002;53:615-627.

10. Sève $P$, Dumontet $C$. Is class III beta-tubulin a predictive factor in patients receiving tubulin-binding agents? Lancet Oncol. 2008;9: $168-175$.

11. Lu Q, Luduena RF. Removal of beta III isotype enhances taxol induced microtubule assembly. Cell Struct Funct. 1993;18:173-182.

12. Kamath K, Wilson L, Cabral F, et al. BetaIII-tubulin induces paclitaxel resistance in association with reduced effects on microtubule dynamic instability. J Biol Chem. 2005;280:12902-12907.

13. Magnani M, Ortuso F, Soro S, et al. The betaI/betaIII-tubulin isoforms and their complexes with antimitotic agents. Docking and molecular dynamics studies. FEBS J. 2006;273:3301-3310.

14. Paradiso A, Mangia A, Chiriatti A, et al. Biomarkers predictive for clinical efficacy of taxol-based chemotherapy in advanced breast cancer. Ann Oncol. 2005;16 Suppl 4:iv14-iv19.

15. Ferrandina G, Zannoni G, Martinelli E, et al. Class III $\beta$-tubulin overexpression is a marker of poor clinical outcome in advanced ovarian cancer patients. Clin Cancer Res. 2006;12:2774-2779.

16. Fojo T, Coley HM. The role of efflux pumps in drug-resistant metastatic breast cancer: new insights and treatment strategies. Clin Breast Cancer. 2007; 7:749-756.

17. Lizard-Nacol S, Genne P, Coudert B, et al. MDR1 and thymidylate synthase (TS) gene expressions in advanced breast cancer: relationships to drug exposure, p53 mutations, and clinical outcome of the patients. Anticancer Res. 1999;19:3575-3581.

18. Rudas M, Filipits M, Taucher S, et al. Expression of MRP1, LRP and Pgp in breast carcinoma patients treated with preoperative chemotherapy. Breast Cancer Res Treat. 2003;81:149-157.

19. Leonessa F, Clarke R. ATP binding cassette transporters and drug resistance in breast cancer. Endocr Relat Cancer, 2003;10:43-73.

20. Trock BJ, Leonessa F, Clarke R. Multidrug resistance in breast cancer: a meta-analysis of MDR1/gp170 expression and its possible functional significance. J Natl Cancer Inst. 1997;89:917-931.
21. Larkin A, O'Driscoll L, Kennedy S, et al. Investigation of MRP-1 protein and MDR-1 P-glycoprotein expression in invasive breast cancer: a prognostic study. Int J Cancer. 2004;112:286-294.

22. Albain KS, Nag S, Calderillo-Ruiz G, et al. Global phase III study of gemcitabine plus paclitaxel (GT) vs. paclitaxel (T) as frontline therapy for metastatic breast cancer (BMC): first report of overall survival. Proc Am Soc Clin Oncol. 2004;22; 14s: abstract 510.

23. Jones SE, Erban J, Overmoyer B, et al. Randomized phase III study of docetaxel compared with paclitaxel in metastatic breast cancer. J Clin Oncol. 2005;23:5542-5551.

24. Seidman AD. Monotherapy options in the management of metastatic breast cancer. Semin Oncol. 2003;30:6-10.

25. Fumoleau P, Largillier R, Clippe C, et al. Multicentre, phase II study evaluating capecitabine monotherapy in patients with anthracyclineand taxane-pretreated metastatic breast cancer. Eur $J$ Cancer. 2004;40:536-542.

26. Miller KD, Chap LI, Holmes FA, et al. Randomized phase III trial of capecitabine compared with bevacizumab plus capecitabine in patients with previously treated metastatic breast cancer. J Clin Oncol. 2005;23:792-799.

27. Geyer CE, Forster J, Lindquist D, et al. Lapatinib plus capecitabine for HER2-positive advanced breast cancer. $N$ Engl J Med. 2006;355:2733-2743.

28. Bollag DM, McQueney PA, Zhu J, et al. Epothilones, a new class of microtubule-stabilizing agents with a taxol-like mechanism of action. Cancer Res. 1995;55:2325-2333.

29. Heinz DW, Schubert WD, Hofle G. Much anticipated-the bioactive conformation of epothilone and its binding to tubulin. Angew Chem Int Ed Engl. 2005;44:1298-1301.

30. Lee FY, Borzilleri R, Fairchild CR, et al. BMS-247550: a novel epothilone analog with a mode of action similar to paclitaxel but possessing superior antitumor efficacy. Clin Cancer Res. 2001;7:1429-1437.

31. Fumoleau P, Coudert B, Isambert N, et al. Novel tubulin-targeting agents: anticancer activity and pharmacologic profile of epothilones and related analogues. Ann Oncol. 2007;18:9-15.

32. Jordan MA, Miller H, Ni L, et al. The Pat-21 breast cancer model derived from a patient with primary Taxol ${ }^{\circledR}$ resistance recapitulates the phenotype of its origin, has altered beta-tubulin expression and is sensitive to ixabepilone. Proc Am Assoc Canc Res. 2006; 47LB-abstract 208.

33. Lee FY, Castaneda S, Inigo I, et al. Ixabepilone (BMS-247550) plus trastuzumab combination chemotherapy induces synergistic antitumor efficacy in HER2 dependent breast cancers and is accompanied by modulation of molecular response markers. Proc Am Soc Clin Oncol. 2005a;23:16s:abstract 561.

34. Lee FY, Castenada S, Hawken D, et al. Bevacizumab/ixabepilone (BMS-247550) combination produces synergistic antitumor efficacy in multiple tumor models in vivo and is superior to bevacizumab/paclitaxel combination. Proc Am Assoc Canc Res. 2005b;abstract B246.

35. Lee FY, Camuso A. Preclinical efficacy evaluation of ixabepilone (BMS-247550) in combination with cetuximab or capecitabine in human colon and lung carcinoma xenografts. Proc Am Soc Clin Oncol. 2006;24:18s:abstract 12017.

36. Jure-Kunkel MN, Masters G, Girit E, et al. Antitumor activity of anti-CTLA-4 monoclonal antibody $(\mathrm{mAb})$ in combination with ixabepilone in preclinical tumor models. J Clin Oncol. 2008; 26(May 20 suppl); abstract 3048.

37. Roché H, Yelle L, Cognetti F, et al. Phase II clinical trial of ilxabepilone (BMS-247550), an epothilone b analog, as first-line therapy in patients with metastatic breast cancer Previously treated with anthracycline chemotherapy. J Clin Oncol. 2005;25:3415-3420.

38. Thomas E, Tabernero J, Fornier M, et al. Phase II clinical trial of ixabepilone (BMS-247550), an epothilone $b$ analog, in patients with taxaneresistant metastatic breast cancer. J Clin Oncol. 2007;25:3399-3406.

39. Perez EA, Lerzo G, Pivot X, et al. Efficacy and safety of ixabepilone (BMS-247550) in a phase II study of patients with advanced breast cancer resistant to an anthracycline, a taxane, and capecitabine. J Clin Oncol. 2007;25:3407-3414. 
40. Denduluri N, Low JA, Lee JJ, et al. Phase II trial of ilxabepilone, an epothilone $\mathrm{b}$ analog, in patients with metastatic breast cancer previously untreated with taxanes. J Clin Oncol. 2007;25:3421-3427.

41. Low JA, Wedam SB, Lee JJ, et al. Phase II clinical trial of ixabepilone (BMS-247550), an epothilone B analog, in metastatic and locally advanced breast cancer. J Clin Oncol. 2005;23:2726-2734.

42. Bunnell C, Vahdat L, Schwartzberg, et al. Phase $1 / 2$ study of ixabepilone plus capecitabine in anthracycline pretreated/resistant and taxane resistant metastatic breast cancer. Clin Breast Cancer. 2008 $8: 234-241$.

43. Thomas E, Gomez HL, Li RK, et al. Ixabepilone plus capecitabine for metastatic breast cancer progressing after anthracycline and taxane treatment. J Clin Oncol. 2007b;25:5210-5217.

44. Thomas E. Ixabepilone plus capecitabine for metastatic breast cancer progressing after anthracycline and taxane treatment. J Clin Oncol. 2008;26:2223.

45. Pivot X, Dufresne A, Villanueva C. Efficacy and safety of ixabepilone, a novel epothilone analogue. Clin Breast Cancer. 2007a;7:543-49.

46. IXEMPRA [package insert]. Princeton, NJ: Bristol-Myers Squibb Co; 2007. Available at: http//packageinserts.bms.com/pi/pi_ixempra.pdf. Accessed May 14, 2009.

47. Takimoto $\mathrm{CH}$, Liu PY, Lenz H, et al. A phase I pharmacokinetic (PK) study of the epothilone B analogue, ixabepilone (BMS-247550) in patients (pts) with advanced malignancies and varying degrees of hepatic impairment. A SWOG Early Therapeutics Committee and NCI Organ Dysfunction Working Group Trial. Proc Am Soc Clin Oncol, 2006 24; 18s:abstract 2004.

48. Rugo HS, Thomas ES, Lee RK, et al. Combination therapy with ixabepilone plus capecitabine compared to capecitabine alone in patients with metastatic breast cancer (MBC) previously treated or resistant to an anthracycline and resistant to taxanes. Presented at the 30th Annual San Antonio Breast Cancer Symposium. 2007.

49. Dent R, Trudeau M, Pritchard KI, et al.Triple-negative breast cancer: clinical features and patterns of recurrence. Clin Cancer Res. 2007; 13:4429-4434.

50. Morris GJ, Naidu S, Topham AK, et al. Differences in breast carcinoma characteristics in newly diagnosed African-American and Caucasian patients: a single-institution compilation compared with the National Cancer Institute's Surveillance, Epidemiology, and End Results database. Cancer. 2007;110:876-884.

51. Bauer KR, Brown M, Cress RD, et al. Descriptive analysis of estrogen receptor (ER)-negative, progesterone receptor (PR)-negative, and HER2-negative invasive breast cancer, the so-called triple-negative phenotype: a population-based study from the California cancer Registry. Cancer. 2007;109:1721-728.
52. Lerma E, Peiro G, Ramon T, et al. Immunohistochemical heterogeneity of breast carcinomas negative for estrogen receptors, progesterone receptors and Her2/neu (basal-like breast carcinomas). Mod Pathol. 20:1200-1207.

53. Roché H, Perez EA, et al. Ixabepilone, an epothilone B analog, is effective in ER, PR, HER-2 negative (triple negative) patients )PTS): data from neoadjuvant and metastatic breast cancer (MBC) trials. Ann Oncol. 2006;17:ix97-ix98.

54. Baselga J, Zambetti M, Llombart-Cussac A, et al. Phase II genomics study of ixabepilone as neoadjuvant treatment for breast cancer. J Clin Oncol. 2009;27:526-534.

55. Pivot X, Lee R, et al. Phase III study of ixabepilone plus capecitabine in patients with metastatic breast cancer (MBC) resistant to anthracyclines/taxanes: subgroup analysis by estrogen receptor (ER) status. Presented at the American Society of Clinical Oncology Breast Cancer Symposium 2007; abstract 221.

56. Lerzo G, Lee RK, Thomas ES, et al. Phase III study of ixabepilone plus capecitabine in matastatic breast cancer (MBC) progressing after anthracyclines and taxanes: subgroup analysis in HER2+ disease. Presented at the American Society of Clinical Oncology Breast Cancer Symposium 2007; abstract 151.

57. Yardley DA, Thomas E, Jassem J, et al. Ixabepilone activity in patients with primary resistance to taxanes. Presented at the 4th ISC International Conference on Cancer Therapeutics, 2007; Toronto, Canada.

58. Gralow JR. Optimizing the treatment of metastatic breast cancer. Breast Cancer Res Treat. 2005;89:S9-S15.

59. Hortobagyi GN, Perez E, Vrdoljak E, et al. Analysis of overall survival (OS) among patients (pts) with metastatic breast cancer (MBC) receiving either ixabepilone (I) plus capecitabine (C) or C alone: Results from two randomized phase III trials. Presented at the 2008 ASCO Breast Cancer Symposium. September 5-7. Washington, DC. Abstract 186.

60. Conte P, Roche H, Perez E, et al. Ixabepilone plus capecitabine improves overall survival in symptomatic patients with metastatic breast cancer previously treated with anthracycline and taxane in 2 large phase III studies. Presented at the 31st Annual San Antonio Breast Cancer Symposium. 2008; December 10-14. San Antonio, TX. Abstract 6114.

61. Roché H, Zambetti M, Dalenc F, et al. Phase Ib study of ixabepilone (I) in combination with epirubicin (E) in women with metastatic breast cancer. Presented at the 2008 ASCO Breast Cancer Symposium.2008 September 5-7. Washington, DC. Abstract 1058.

62. Tolaney SM, Najita J, Chen W, et al. [3137] A phase II study of ixabepilone plus trastuzumab for metastatic HER2-positive breast cancer. Presented at the 31st Annual San Antonio Breast Cancer Symposium. 2008; December 10-14. San Antonio, TX. Abstract 3137.

\section{Publish your work in this journal}

Drug Design, Development and Therapy is an international, peerreviewed open-access journal that spans the spectrum of drug design and development through to clinical applications. Clinical outcomes, patient safety, and programs for the development and effective, safe, and sustained use of medicines are a feature of the journal,

\section{Dovepress}

which has also been accepted for indexing on PubMed Central. The manuscript management system is completely online and includes a very quick and fair peer-review system, which is all easy to use. Visit http://www.dovepress.com/testimonials.php to read real quotes from published authors 